\title{
Prediction of Loss on Ignition of Ternary Cement Containing Coal Bottom Ash and Limestone Using Central Composite Design
}

\author{
Olumide Olu Olubajo ${ }^{1}$, Isa Yusuf Makarfi ${ }^{2}$, Osha Ade Odey ${ }^{2}$ \\ ${ }^{1}$ Abubakar Tafawa Balewa University \\ Dass road, P. M. B. 0248, Bauchi, 740272, Nigeria \\ ${ }^{2}$ Durban University of Technology \\ P. 0. Box 1334, Durban, 4000, South Africa \\ ${ }^{3}$ University of Calabar \\ Etagbor, P. M. B. 1115, Cross River State, Nigeria
}

DOI: $10.22178 /$ pos.49-3

LCC Subject Category: QD1-65

Received 28.06.2019

Accepted 30.08.2019

Published online 31.08.2019

Corresponding Author:

Olumide Olu Olubajo

ooolubajo@atbu.edu.ng

(c) 2019 The Authors. This article

is licensed under a Creative

Commons Attribution 4.0 License

(c) (1)
Abstract. The effect of $C B A / C B A-L$ ratio and the cement replacement on the Loss on ignition (LOI) of ternary cement blends was investigated using central composite design approach in the prediction of LOI of ternary cement blend comprising of Ordinary Portland cement, coal bottom ash and Limestone. LOI is an essential technique employed in the determination of the quality of the cement blend which can be achieved by heating a sample strongly at a specified temperature to enable release of volatile components until the weight remains constant. In this study, monitoring of the LOI of the various cement blends conducted dependent on cement replacement and coal bottom ash to coal bottom ash-limestone ratio (CBA/CBA-L ratio) via thermogravimetric analysis (TGA) and X-ray fluorescence (XRF) analysis. The CBA/CBA-L ratio was varied from $0.25-0.75$ while the cement replacement ranges from $20-40 \%$. The significance of these factors within the specified ranges considered was evaluated using analysis of variance. The aim of the study was to evaluate the effect of CBA/CBA-L ratio and cement replacement in the prediction of LOI for ternary cement blends by employing Face Central Composite Design. Analysis of variance results indicated that the $\mathrm{LOI}$ prediction via XRF analysis was better than that of TG analyses in which both satisfied Two-Level Factorial model. It was observed from the predictive models that the LOI of the ternary cement decreased as the CBA/CBA-L ratio was increased while LOI of the ternary cement blend increased as the cement replacement was increased. An increase in both CBA/CBA-L ratio and cement replacement resulted in a decrease in the LOI of ternary cement. The cement replacement level of the ternary cement blends indicated a stronger influence on LOI compared to the CBA/CBA-L ratio which was indicated by a significantly high $F$ value for cement replacement compared to CBA/CBA-L ratio. The LOI results from XRF analysis were also found to significantly predict the LOI of the ternary cement blend compared to TGA with Regression value of $99.96 \%$ against $97.36 \%$ respectively. The $C B A / C B A-L$ ratio and cement replacement were found to have a significant and interactive effect on the LOI of ternary cement blend for both XRF and TGA analyses.

Keywords: prediction; loss on Ignition; cement replacement; coal bottom ash to coal bottom ash-limestone ratio; central composite design.

\section{INTRODUCTION}

The continuous generation of waste which possesses both hydraulic and pozzolanic properties via pyro processes along with environmental concerns has given rise to the need to effectively utilize ashes as pozzolana to improve the physico-mechanical properties and durability of ce- ment $[1,2,3]$. Various successes in the use of ashes ranging from fly ash [4], coal bottom ash $[5,6]$, rice husk ash $[7,8]$. Loss on ignition (LOI) is one of the quickest and cheapest techniques employed in the determination of the quality of the cement blend. It is a key cement property that affects the quality of cement blends contain- 
ing pozzolanas like slags, coal bottom ash, rice husk ash, corn cob ash [9] etc., which are associated with the amount of moisture and carbonates present $[10,11]$. Loss on ignition of coal bottom ash or cement blends can be determined by heating a sample strongly at a specified temperature to enable release of volatile components until the weight remains constant [12]. The value of the Loss on ignition can be considered as a determinant for unburned carbon degree of bottom ash $[6,13]$. According to [14], the LOI of cement or types of cement can be achieved practically by heating up ten grams in a platinum crucible at a temperature of 900 to $1000{ }^{\circ} \mathrm{C}$ for 15 minutes [12]. The weight losses of cement blends during heating could be due to the evaporation or volatilization of a variety of components of the sample and some of the components lost include water at $100-105{ }^{\circ} \mathrm{C}$, organic material which is burnt off at about $550{ }^{\circ} \mathrm{C}$, while most of the carbonates decompose between $800-1000^{\circ} \mathrm{C}$ [15].

The quality and reactivity of the pozzolan could be influenced due to pre-hydration and carbonation owing to improper and prolonged storage of the cement sample or adulteration during transportation of the material (high LOI), thus, impacting on its performance [11]. The importance of the knowledge of the LOI cannot be overemphasized as it can also be employed as an indicator in monitoring the quality of the final product during clinker production $[15,26]$. The loss on ignition of the coal bottom ash, cement or cement blend is the amount of weight loss through raising the temperature of the material to a predetermined level. These losses in weight could be due to moisture and carbon dioxide causes weight loss which should not exceed $5 \%$ for all types of cement. Most of the pozzolans such as coal bottom ash $[3,5,6,17]$, fly ash $[4,17,18]$, rice husk ash [19], corn cob ash [9] and other biomasses to a large extent exhibits loss on ignition values ranging from $2-10 \%$. In order to successful determine the quality of the cement blends/ pozzolans and reduce the cumbersome task of determining the LOI test manually, the need to provide a predictive model for the determination of the LOI of cement blended with limestone and coal bottom ash which could ascertain the quality of the cement blend employed [16]. Response surface methodology (RSM) is a set of the statistical or mathematical technique employed to evaluate the effect of several factors on a given response
[20]. Amongst other design models under response surface methodology is the central composite design. The central composite design has been found to provide relevance in various areas such as the construction/building sector as well as other engineering sectors with confidence level ranging from 83-99 \% to establish a correlation between response and the factor to be considered and it is effective in providing insight on the interaction between the factors and responses. One of the successes includes the prediction of mortar compressive strengths for various construction applications with a high confidence level of about $90 \%$ according to [16].

Previous work by [6] investigated the effect of limestone and Coal bottom ash as a partial replacement on the LOI of ternary cement blends. This paper tries to provide a model for the prediction /determination of the LOI of ternary cement blends containing OPC, limestone and coal bottom ash using response surface methodology via Central composite design. The developed model was investigated to determine the effect of cement replacement and composition of the cement blend (ratio of the pozzolana/cement replacement content), CBA/CBA-L ratio for the determination of the LOI of the cement blend.

\section{MATERIALS AND METHODS}

Table 1 indicates the design summary for determining the loss of ignition via TGA and XRF analysis (responses) and how CBA/CBA-L ratio and cement replacement level affect the two responses, the following parameters were chosen as independent variables: CBA/CBA-L ratio $(0.25$, $0.50,0.75)$, while the cement replacement level $(20,30,40 \%)$. Face central composite factorial design (3 level 2 factors) with 9 runs (1 block) (Design expert 6.0.8) where -1 denotes low value of the independent variable $(0.25,20 \%), 0$ used for the medium value $(0.50,30 \%)$ and for the high value $(0.75,40 \%)$. A model was fitted to the response surface generated by the experiment.

Table 2 indicates the experimental results for the Loss on ignition of the ternary blend via TG method and XRF analysis obtained from the calcination of alum derived from kaolin clay to alumina at various temperatures and times for cement replacement levels from $20-40 \%$ and CBA/CBA-L ratio from $0.25-0.75$. 
Table 1 - Design Summary

\begin{tabular}{|c|c|c|c|c|c|c|c|}
\hline Study Type & Response Surface & Experiments & 9 & & & & \\
\hline Initial Design & Central Composite & Blocks & \multicolumn{2}{|c|}{ No Blocks } & & & \\
\hline Design Model & \multicolumn{2}{|c|}{ Quadratic } & & & & & \\
\hline Response & Name & Units & Obs & Minimum & Maximum & Trans & Model \\
\hline $\mathrm{Y}_{1}$ & LOI TGA & $\%$ & 9 & 8.1 & 14.2 & None & Quadratic \\
\hline $\mathrm{Y}_{2}$ & LOI XRF & $\%$ & 9 & 6.54 & 15.51 & None & $2 \mathrm{FI}$ \\
\hline Factor & Name & Units & Type & Low Actual & High Actual & Low Coded & High Coded \\
\hline $\mathrm{X}_{1}$ & \multicolumn{2}{|c|}{ CBA/CBA-L ratio } & Numeric & 0.25 & 0.75 & -1 & 1 \\
\hline $\mathrm{X}_{2}$ & cement replacement & $\%$ & Numeric & 20 & 40 & -1 & 1 \\
\hline
\end{tabular}

The analysis of variance (ANOVA) and response surface method (RSM) were conducted using design expert 6.0.8 program and presented in Table 3 .

The model was obtained for each dependent variable (or response) where the factors were rejected when their significance level was less than $\mathrm{p}<0.05$, confidence limit $95 \%$. The design expert 6.0.8 was used to produce contour plots and graph.

Table 2 - Experimental design and results

\begin{tabular}{|c|c|c|c|c|}
\hline $\begin{array}{c}\mathrm{N} \\
\mathrm{o}\end{array}$ & $\begin{array}{c}\text { CBA/CBA-L } \\
\text { ratio }\end{array}$ & $\begin{array}{c}\text { Cement } \\
\text { Replacement, } \\
\%\end{array}$ & $\begin{array}{c}\text { LOI } \\
\text { TGA, } \\
\%\end{array}$ & $\begin{array}{c}\text { LOI } \\
\text { XRF, } \\
\%\end{array}$ \\
\hline 1 & 0.25 & 30 & 13.45 & 12.94 \\
\hline 2 & 0.25 & 40 & 14.20 & 15.51 \\
\hline 3 & 0.50 & 40 & 11.00 & 11.91 \\
\hline 4 & 0.75 & 20 & 8.10 & 6.54 \\
\hline 5 & 0.25 & 20 & 11.20 & 10.08 \\
\hline 6 & 0.50 & 30 & 9.90 & 10.10 \\
\hline 7 & 0.75 & 40 & 8.40 & 8.28 \\
\hline 8 & 0.75 & 30 & 8.25 & 7.35 \\
\hline 9 & 0.50 & 20 & 9.60 & 8.43 \\
\hline
\end{tabular}

Table 3 - ANOVA for Response Surface Model Analysis of variance for LOI of ternary cement blend for TGA \& XRF with Central Composite Design CCD

\begin{tabular}{|l|c|c|c|c|c|c|}
\hline \multicolumn{1}{|c|}{ Source } & Sum of Squares & DF & Mean Square & F Value & Prob $>\mathrm{F}$ & \\
\hline Model $\mathrm{Y}_{1}$ & 38.64 & 3 & 12.88 & 66.9 & $<0.0001$ & Significant \\
\hline $\mathrm{X}_{1}$ & 33.14 & 1 & 33.14 & 172.1 & $<0.0001$ & Significant \\
\hline $\mathrm{X}_{2}$ & 3.68 & 1 & 3.68 & 19.12 & 0.0018 & Significant \\
\hline $\mathrm{X}_{1} \mathrm{X}_{2}$ & 1.82 & 1 & 1.82 & 9.47 & 0.0132 & \\
\hline Residual & 1.73 & 9 & 0.19 & & & \\
\hline Lack of Fit & 1.73 & 5 & 0.35 & & & \\
\hline Model $\mathrm{Y}_{2}$ & 66.92 & 3 & 22.31 & 7400.15 & $<0.0001$ & Significant \\
\hline $\mathrm{X}_{1}$ & 44.61 & 1 & 44.61 & 14799.5 & $<0.0001$ & Significant \\
\hline $\mathrm{X}_{2}$ & 18.90 & 1 & 18.90 & 6271.62 & $<0.0001$ & Significant \\
\hline $\mathrm{X}_{1} \mathrm{X}_{2}$ & 3.40 & 1 & 3.40 & 1129.34 & $<0.0001$ & Significant \\
\hline Residual & 0.027 & 9 & $3.01 \mathrm{E}-03$ & & & \\
\hline Lack of Fit & 0.027 & 5 & $5.43 \mathrm{E}-03$ & & & \\
\hline
\end{tabular}

\section{RESULTS AND DISCUSSION}

Face central composite design was employed and the factors required include Coal bottom ash to coal bottom ash- limestone ratio (CBA/CBA-L ratio) and cement replacement with their responses; Loss on ignition of cement blend for TG and XRF analyses respectively. The effect of the various factors on the responses were determined using design expert 6.0.8. These equations (1)-(2) represent quantitative effect of the factor's variables; CBA/CBA-L ratio and cement replacement $\left(\mathrm{X}_{1}, \mathrm{X}_{2}\right)$ and their interactions on the response; LOI via TGA and LOI via XRF $\left(\mathrm{Y}_{1}, \mathrm{Y}_{2}\right)$ respectively. The values of $\mathrm{X}_{1}$ and $\mathrm{X}_{2}$ were then substituted in the equation to obtain the theoretical value of $\mathrm{Y}_{1}$ and $\mathrm{Y}_{2}$ respectively.

$\mathrm{LOI}_{\mathrm{TGA}}=\mathrm{Y}_{2}=+8.58462-1.300 \mathrm{X}_{1}+$

$0.21333 \mathrm{X}_{2}-0.2700 \mathrm{X}_{1} \mathrm{X}_{2}$

$\mathrm{LOI}_{\mathrm{XRF}}=\mathrm{Y}_{2}=+4.71179+0.16333 \mathrm{X}_{1}+$

$0.362 \mathrm{X}_{2}-0.369 \mathrm{X}_{1} \mathrm{X}_{2}$

The CBA/CBA-L ratio, $\left(\mathrm{X}_{1}\right)$ obtained a $\mathrm{F}$ value of 172.1 and 14,799.50, while for the cement re- 
placement $\left(\mathrm{X}_{2}\right)$ produced a $\mathrm{F}$ value of 19.12 and 6,271.62 for TG and XRF analyses respectively. The high $F$ value is a strong indication that the effect of the CBA/CBA-L ratio has a far more significant compared to the cement replacement while the product of interaction terms obtained very low $\mathrm{F}$ values of 9.47 while for XRF analysis obtained a relatively high $F$ value of 1129.34 respectively with $\mathrm{p}$ values of $>0.05$ respectively. The analysis of variance showed the significant effect of the independent variables on the responses and determined that the responses were significantly affected by the various interactions. Table 3 indicates the analysis of variance for LOI via $\mathrm{TG}$ and $\mathrm{XRF}$ analyses both gave insignificant lack of fit values of 0.35 and 0.00543 respectively. It could be concluded that both factors $\mathrm{X}_{1}$ and $\mathrm{X}_{2}$ significantly affected both responses.

The first and second responses were both suitable for 2 factorial level model to predict the function response for all the dependent variables. The linear term of CBA/CBA-L ratio, cement replacement and their interaction were statistically significant for the determination of the LOI for TG and XRF analyses of ternary cement blend. This is because the $p$ values fell within $p<0.05$ or $p<0.10$ for the interaction between both factors for both responses were statistically significant. From the analyses both responses indicated that the linear terms for cement replacement was more significant having high $F$ value (172.1/14799.50) compared with that of CBA/CBA-L ratio (19.12/ 6271.62). Thus, the CBA/CBA-L ratio was found to contribute substantially in the generation of either of the two models. Similarly, the interaction of the CBA/CBA-L ratio and cement replacement was also found to exist which was more significant at $\mathrm{p}<0.05$ or $\mathrm{p}<0.10$ for the model for LOI via XRF analysis compared to LOI via TG analysis. The residual variance for the models were insignificant thus indicates the error term representing the lack of fit variation [21]. Both models had insignificant lack of fit tests which means that the model represents the data satisfactorily. The relatively high $\mathrm{R}^{2}$ value is an indicator that the variation observed and the data fitted satisfactorily for Two Level factorial level model for LOI via TG and XRF analyses with $\mathrm{R}^{2}$ value of $95.71 \%$ and $99.86 \%$ respectively. Thus, indicating a good fit of the model to experimental results.

Based on the experimental design and factor combination, amongst the other models, two level Factorial model was found to be significant for LOI of cement blends via TGA and XRF analyses as shown in Table 4 and 5 respectively.

Table 4 - Model Summary Statistics/ Sequential Model Sum of Squares for CCD for LOI via TGA

\begin{tabular}{|l|c|c|c|c|c|c|c|c|c|c|}
\hline \multicolumn{1}{|c|}{ Source } & Sum of Squares & $\mathrm{DF}$ & $\mathrm{F}$ value & Prob> F & Std. Dev. & $\mathrm{R}^{2}$ & Adj. $^{2}$ & Pred. ${ }^{2}$ & PRESS & \\
\hline Linear & 36.82 & 2 & 51.78 & $<0.0001$ & 0.60 & 0.9119 & 0.8943 & 0.7997 & 8.09 & \\
\hline 2FI & 1.82 & 1 & 9.47 & 0.0132 & 0.44 & 0.9571 & 0.9428 & 0.8988 & 4.09 & Suggested \\
\hline Quadratic & 1.11 & 2 & 6.24 & 0.0278 & 0.30 & 0.9846 & 0.9736 & 0.8775 & 4.94 & Suggested \\
\hline Cubic & 0.21 & 2 & 1.26 & 0.3611 & 0.29 & 0.9897 & 0.9754 & -0.1922 & 48.13 & Aliased \\
\hline
\end{tabular}

It was suggested that a fitted model can be considered to be acceptable when the $\mathrm{R}^{2}$ is not less than $80 \%$ and greater than $75 \%$ respectively according to [22] and [23]. Table 4 indicates the determination of LOI via TGA and observed that the $\mathrm{R}^{2}$ and predicted $\mathrm{R}^{2}$ were $95.71 \%$ and $89.88 \%$ respectively implying that the predicted model can only represent $89.88 \%$ of the data in determining the LOI via TGA. The PRESS value for LOI via TGA analysis was observed to be relatively high compared with LOI via XRF analysis at 4.94 as indicate in Table 4 . The lower the PRESS value, the better model fit for the experimental data. Thus, the $\mathrm{F}$ value for the model of LOI via XRF was highly significant (1129.34). The $\mathrm{R}^{2}$ and the predicted $\mathrm{R}^{2}$ values was $99.96 \%$ and $99.86 \%$ respectively with a very low PRESS value of 0.094 in comparison with TGA. Thus, indicating that the XRF analysis predicts most acurately the LOI determination of ternary cement blend compared to TGA. In this research work, the developed models for indicated $\mathrm{R}^{2} / \mathrm{R}^{2}$ adj values of 95.71 / 94.28 and 99.96/ 99.95 percent respectively indicating appropriateness of the developed model for the two factors with $\mathrm{R}^{2}$ and $\mathrm{R}^{2}$ adj value close to unity. Authors [24] and [25] stated that a better empirical model fit was obtained with the experimental data when the $\mathrm{R}^{2}$ value is close to unity. It was observed that a relatively high $\mathrm{R}^{2}$ value does not imply that the model is adequate, thus, [23] suggested that a $\mathrm{R}^{2}$ adj of above $90 \%$ is most appropriate to evaluate the model adequacy. 
Table 5 - Model Summary Statistics/ Sequential Model Sum of Squares for CCD for LOI XRF

\begin{tabular}{|l|l|l|l|l|l|l|l|l|l|l|}
\hline \multicolumn{1}{|c|}{ Source } & Sum of Squares & DF & F value & Prob $>$ F & Std. Dev. & $\mathrm{R}^{2}$ & Adj. R & Pred. $\mathrm{R}^{2}$ & PRESS & \\
\hline Linear & 63.51 & 2 & 92.55 & $<0.0001$ & 0.59 & 0.9487 & 0.9385 & 0.853 & 9.84 & \\
\hline 2FI & 3.40 & 1 & 1129.34 & $<0.0001$ & 0.055 & 0.9996 & 0.9995 & 0.9986 & 0.094 & Suggested \\
\hline Quadratic & $7.16 \mathrm{E}-04$ & 2 & 0.095 & 0.9107 & 0.061 & 0.9996 & 0.9993 & 0.9964 & 0.24 & \\
\hline Cubic & 0.018 & 2 & 5.06 & 0.0628 & 0.042 & 0.9999 & 0.9997 & 0.9848 & 1.01 & Aliased \\
\hline
\end{tabular}

Figure 1 indicates the normal probability and the predicted against the actual plots for LOI of the ternary cement blends obtained via TGA and XRF respectively. The normal probability plot indicated a strong linear pattern with only minor deviations from the line fit to the points on the probability plot for determination of the LOI of ternary cement blend obtained by TGA and XRF analysis in figures 1 (a) \& (b) respectively. Thus, the normal distribution appears to be a good model for the set of data employed with the probability plot indicating a strongly linear pattern which is verified by the correlation coefficient of $98.46 \%$ and $99.86 \%$ of line of fit respectively.
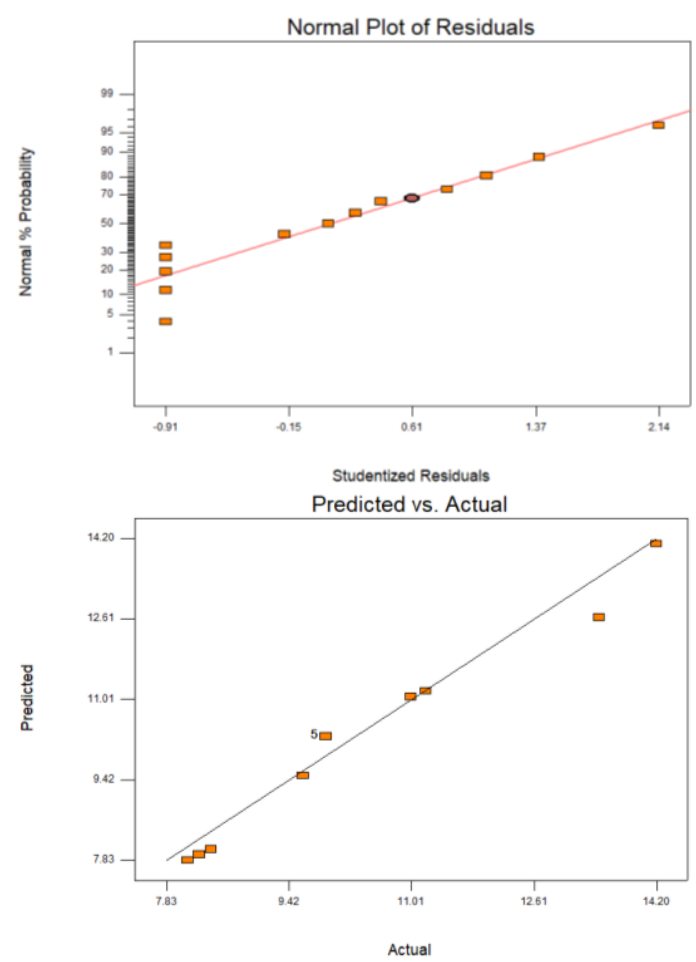

Figure 1 - Predicted vs Actual plot and Normal Plot of residuals indicating significance of the model developed for the LOI of ternary cement blend for TGA results

Figures 2 (a) \& (b) indicated that there is a strong relationship between the predicted and experimental values for LOI of the cement blend obtained via TGA and XRF. Based on the results obtained, it could be inferred that the predicted model by Design Expert was significantly ade- quate in predicting the LOI of the cement blend obtained via TGA and XRF respectively.
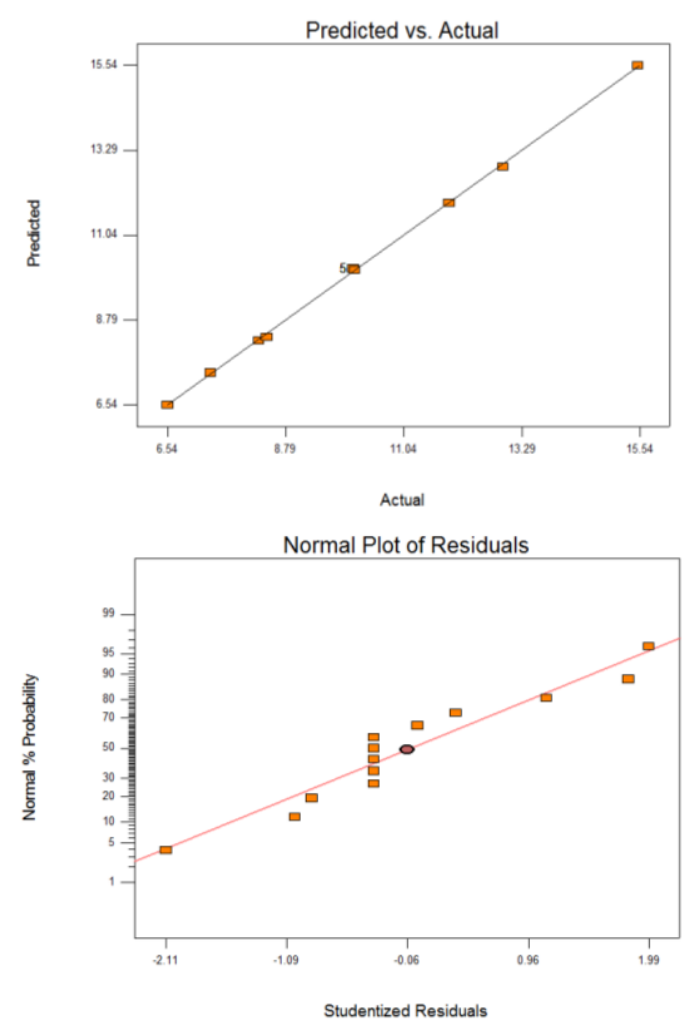

Figure 2 - Predicted vs Actual plot and Normal Plot of residuals indicating significance of the model developed for the LOI of ternary cement blend for XRF results

The relationship between the responses and the factors were further elucidated using contour plots and response surface plot. Figures 3-4 illustrates the contour and 3D response (3D) plots for the effect of factors $\mathrm{X}_{1}$ (CBA/CBA-L ratio), $\mathrm{X}_{2}$ (cement replacement level) on the first response $\mathrm{Y}_{1}$ (LOI of ternary cement via TGA) and second response $\mathrm{Y}_{2}$ (LOI of ternary cement via XRF) respectively.

Figures 5-8 illustrates the effect of CBA/CBA-L ratio at constant cement replacement level on the LOI of ternary cement from TGA and XRF analysis and the effect of cement replacement at constant CBA/CBA-L ratio on the LOI of ternary cement from TGA and XRF analysis respectively. 
From the predictive model for the determination of the LOI via TGA, it could be seen that as the CBA/CBA-L ratio was held constant at 0.25 and the cement replacement was increased from 20$40 \%$, the LOI of the ternary cement blend increased from 11.18-14.09\%. Similar trend of an increase in the LOI of ternary cement was observed for other CBA/CBA-L ratios at 0.5 and 0.75 respectively.

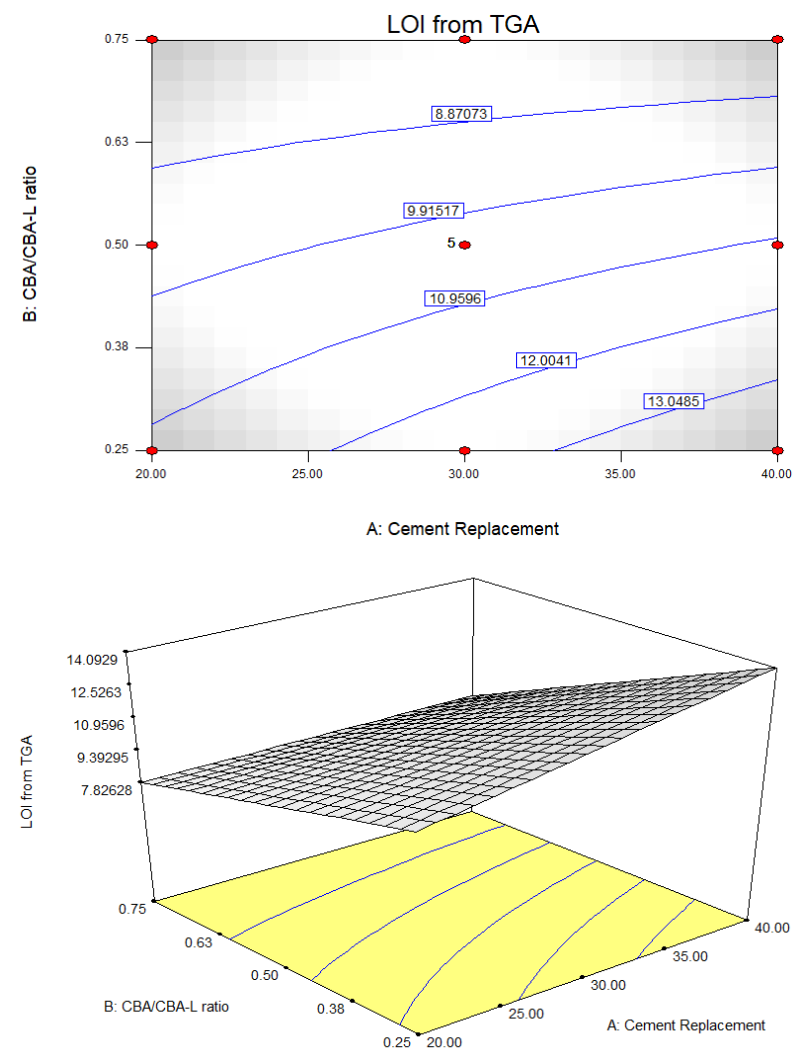

Figure 3 - Response surface plot (3 D surface and contour) showing the effect of different factors $\left(X_{1}\right.$ :

CBA/CBA-L, $X_{2}$ : cement replacement) on LOI of ternary cement blend for Two Level factorial model
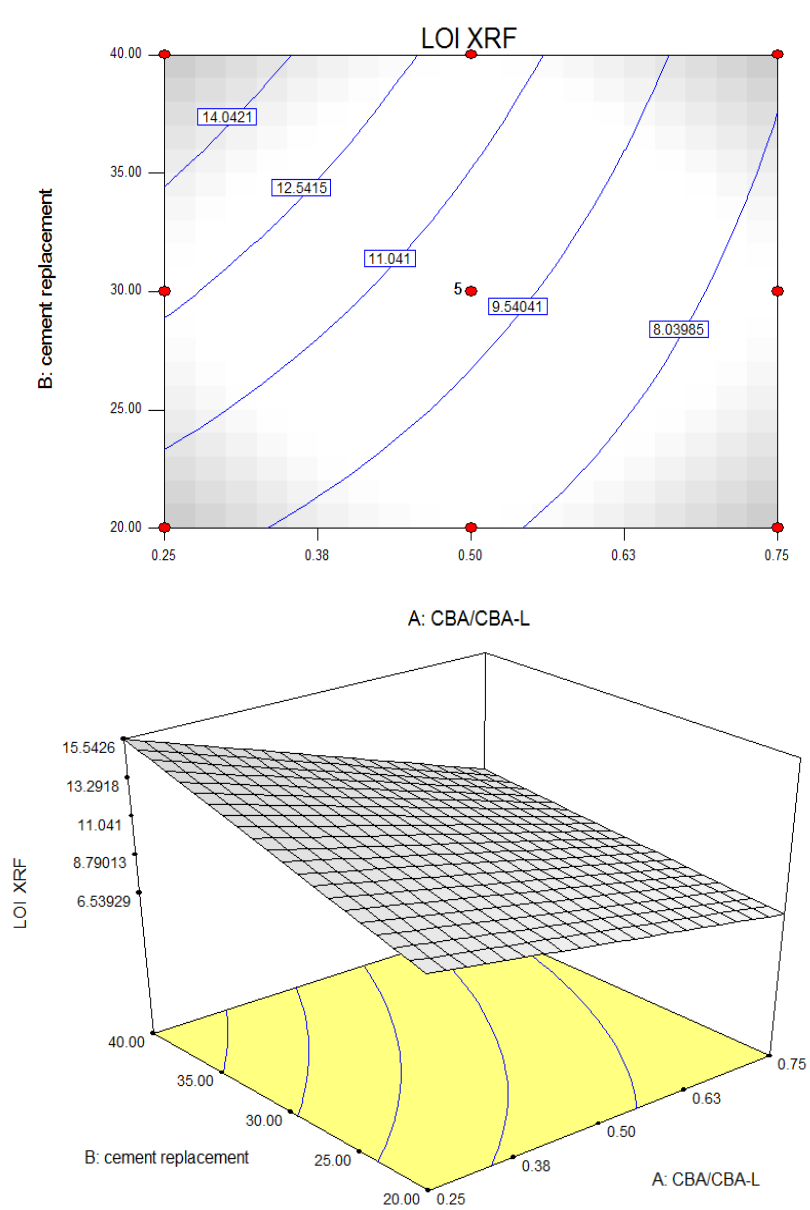

Figure 4 - Response surface plot (3 D surface and contour) showing the effect of different factors $\left(X_{1}\right.$ : $C B A / C B A-L, X_{2}$ : cement replacement) on $L O I$ of ternary cement blend for Two Level Factorial model

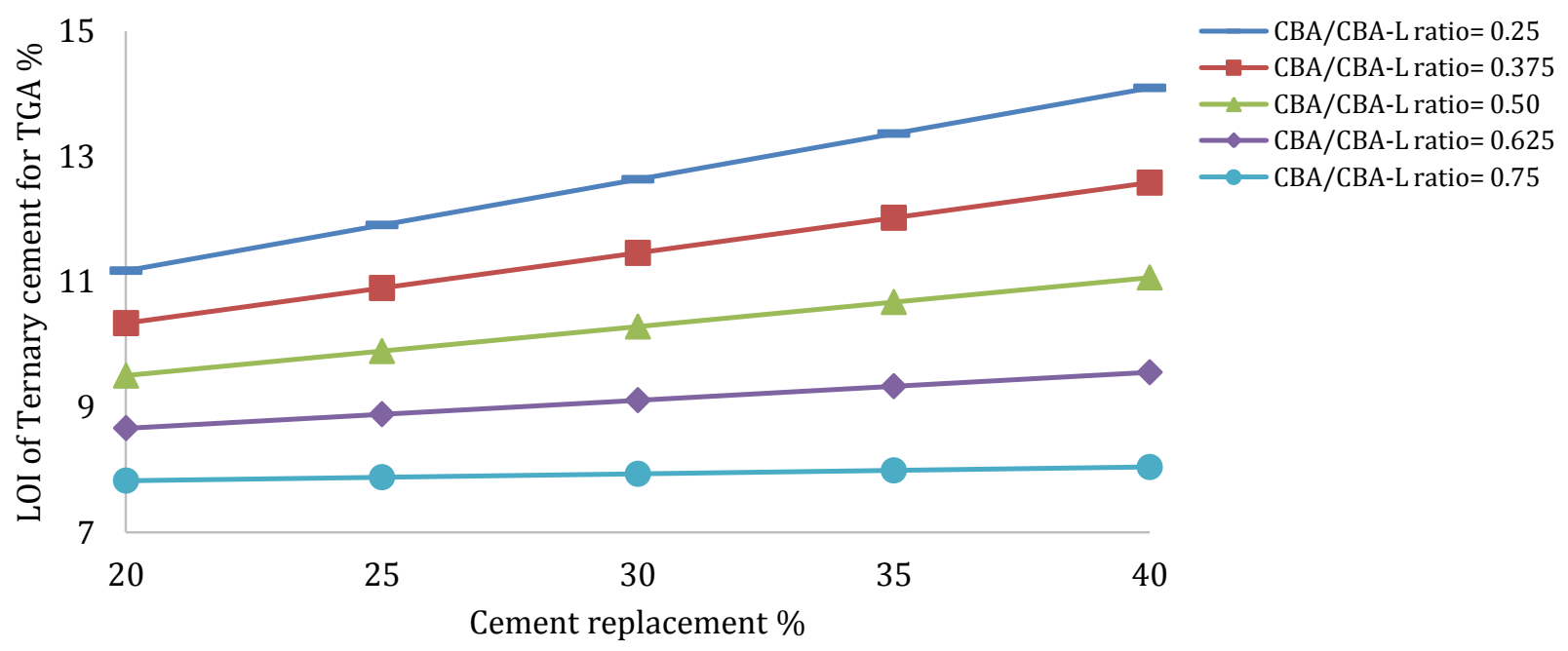

Figure 5 - Effect of cement replacement on the LOI of cement blends via TGA analysis at various CBA/CBA$L$ ratios 


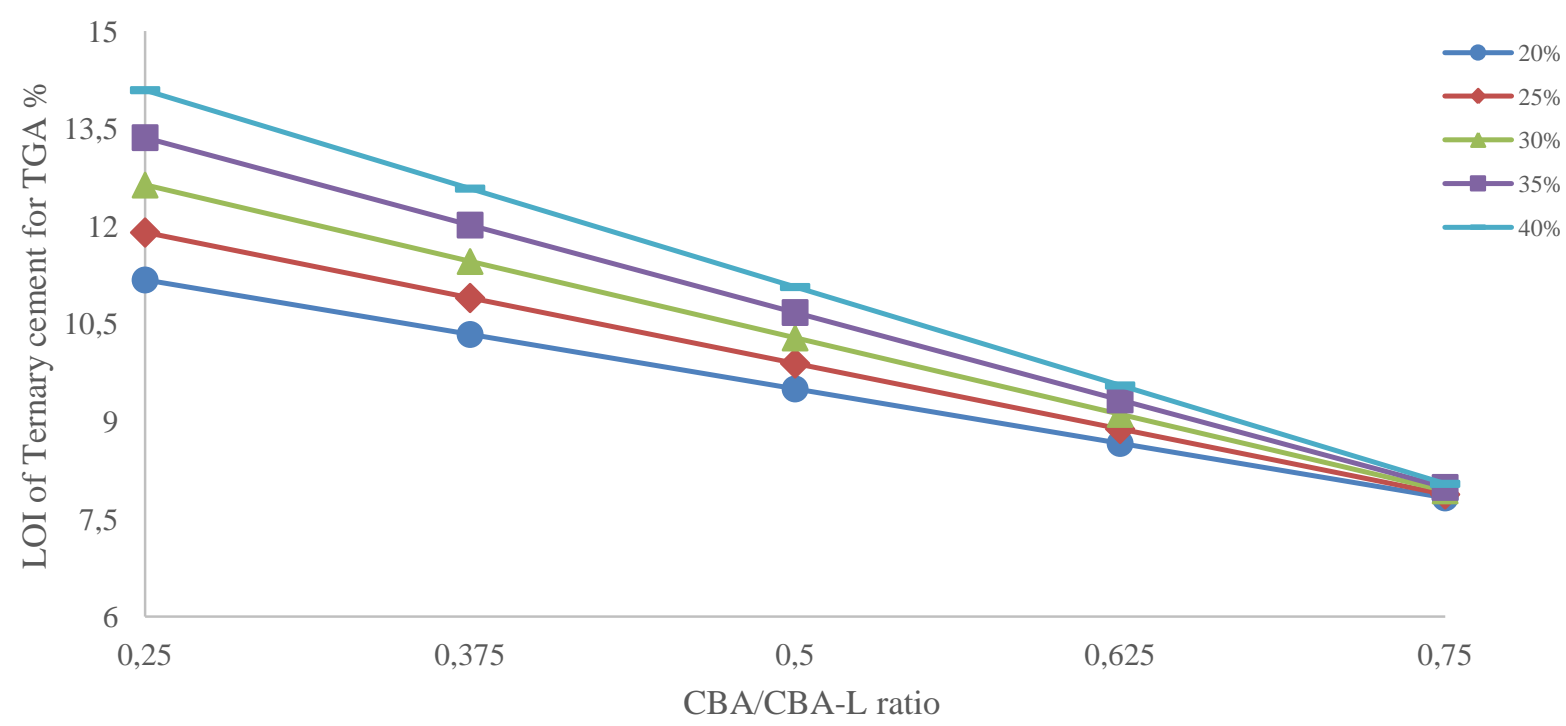

Figure 6 - Effect of CBA/CBA-L ratio on the LOI of cement blends via TGA analysis at various cement replacements

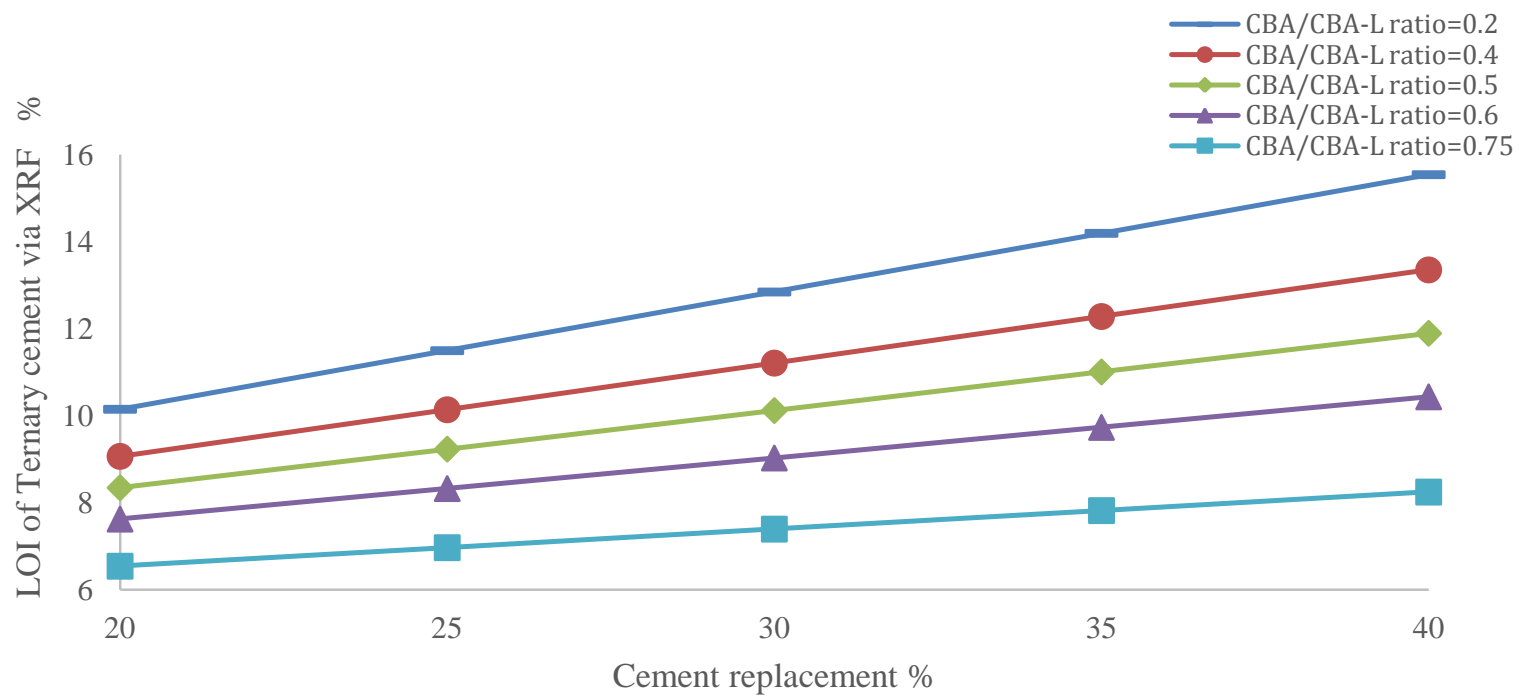

Figure 7 - Effect of cement replacement on the LOI of cement blends via XRF analysis at various CBA/CBA-L ratios

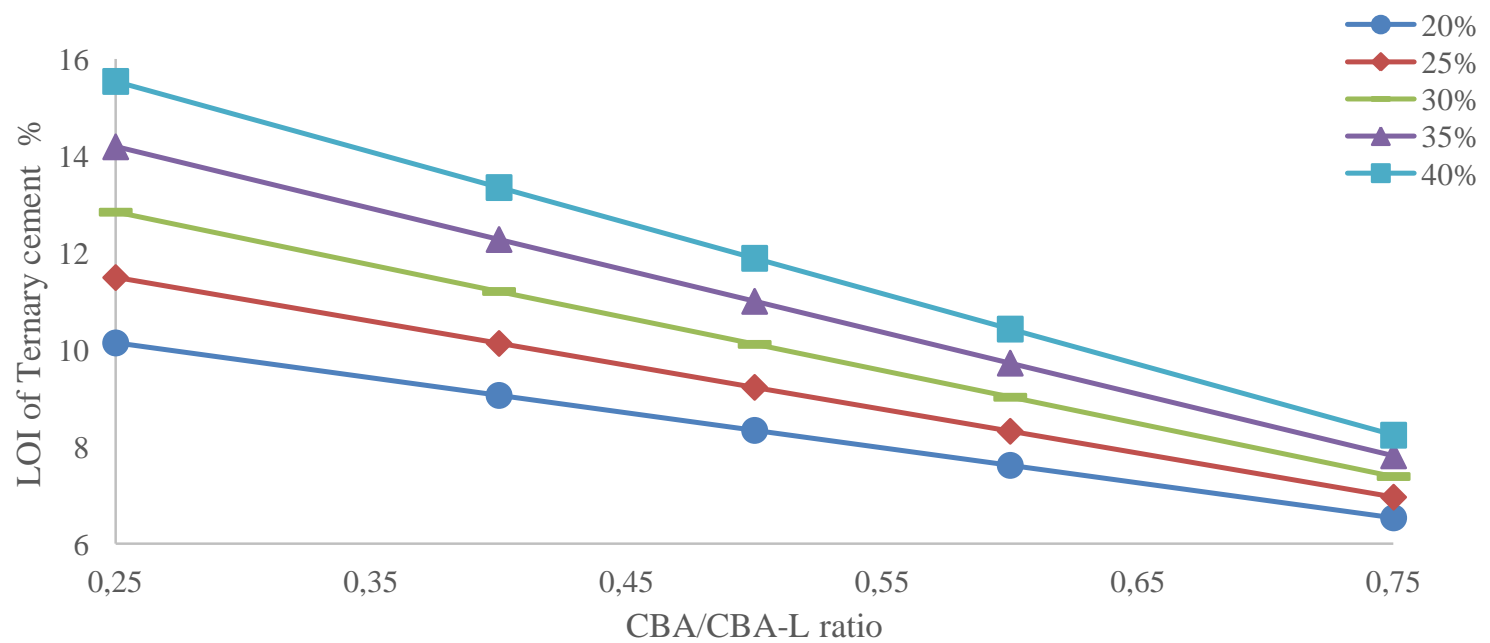

Figure 8 - Effect of CBA/CBA-L ratio on the LOI of cement blends via XRF analysis at various cement replacements 
This decrease in the LOI of the ternary cement could be attributed to the decrease in the limestone content due to the high LOI of limestone according to [17] as the cement replacement was increased despite in increase in CBA content. Whereas, as the CBA/CBA-L ratio was increased from $0.25-0.75$ at cement replacement of 20, 30 and $40 \%$ resulted in a decrease in the LOI values of the ternary cement blends from 11.18 to $7.83 \%, 12.63$ to $7.93 \%$ and 14.09 to $8.04 \%$ respectively.

On the other words, the predictive model for the determination of the LOI via XRF analysis, it could also be observed that the LOI of the ternary cement blends increased as the CBA/CBA-L ratio was held constant at $0.25,0.50$ and 0.75 as the cement replacement level was increased from $20-40 \%$. The LOI of the ternary cement blends decreased as the CBA/CBA-L ratio was increased from $0.25-0.75$ at constant cement replacement of 20,30 and $40 \%$ from 10.15 to $6.52 \%, 12.85$ to $7.39 \%$ and 15.54 to $8.24 \%$ respectively. This decrease could be attributed to the decrease in the limestone content as CBA/CBA-L ratio was increased which is responsible for the high LOI compared to CBA, since CBA LOI is quite low.

The LOI values obtained via XRF analysis were found to be more precise in comparison with TGA owing to the significantly high $\mathrm{R}^{2}$ value of $99.95 \%$ compared to $94.28 \%$.

\section{CONCLUSION}

In conclusion, the CBA/CBA-L ratio and cement replacement were found to have a significant and interactive effect on the LOI of ternary cement blend for TG and XRF analyses with the predictive models which both satisfied Two level Factorial model. Similarly, both responses indicated a gradually decrease in the LOI of the ternary cement blend as the CBA/CBA-L ratio was increased while the LOI of ternary cement blends increased as the cement replacement level was increased. Both responses experienced a higher LOI as the cement replacement of the ternary cement blends was gradually increased which could be attributed to the quantity of CBA and limestone presence during the thermal decomposition of the ternary cement blends. The ANOVA results indicated that the cement replacement produced a more significant effect on the responses in comparison with CBA/CBA-L ratio observed by the significantly high $F$ value. Thus, indicating that the XRF analysis predicted most acurately the LOI determination of ternary cement blend compared to TGA with the developed models for $\mathrm{R}^{2} / \mathrm{R}^{2}$ adj values of $98.46 / 97.36$ and 99.96/99.95 percent respectively.

\section{ACKNOWLEDGMENT}

The authors acknowledge Ashaka Cement Plc for their support to this research work.

\section{REFERENCES}

1. Khalil, E. A. B., \& Anwar, M. (2015). Carbonation of ternary cementitious concrete systems containing fly ash and silica fume. Water Science, 29(1), 36-44. doi: 10.1016/j.wsj.2014.12.001

2. Lothenbach, B., Scrivener, K., \& Hooton, R. D. (2011). Supplementary cementitious materials. Cement and Concrete Research, 41(12), 1244-1256. doi: 10.1016/j.cemconres.2010.12.001

3. Olubajo, O., Osha, O., El- Nafaty, U., \& Adamu, H. (2014). Effect of water-cement ratio on the mechanical properties of blended cement containing bottom ash and limestone. Civil and Environmental Research, 6(12), 1-9.

4. De Weerdt, K., Kjellsen, K. O., Sellevold, E., \& Justnes, H. (2011). Synergy between fly ash and limestone powder in ternary cements. Cement and Concrete Composites, 33(1), 30-38. doi: 10.1016/j.cemconcomp.2010.09.006

5. Kaya, A. (2010). A study on blended bottom ash cements. Retrieved from https://ru.scribd.com/document/230376452/A-Study-on-Blended-Bottom-Ash-CementsTaban-Kulu-Katk\%C4\%B11\%C4\%B1-Cimentolara-Yonelik-Bir-Cal\%C4\%B1\%C5\%9Fma

6. Olubajo, O., \& Osha, O. (2013). Influence of bottom ash and limestone powder on the properties of ternary cement and mortar. International Journal of Engineering Research and Technology, 2(7), 1201-1212. 
7. Marthong, C. (2012). Effect of Rice Husk Ash (RHA) as Partial Replacement of Cement on Concrete Properties. International Journal of Engineering Research \& Technology, 1(6), 1-9.

8. Kulkarni, M., Govind Mirgal, P., Bodhale, P., \& Tande, S. (2014). Effect of Rice Husk Ash on Properties of Concrete. Journal of Civil Engineering and Environmental Technology, 1(1), 26-29.

9. Raheem, A., \& Adesanya, A. (2011). A study of thermal conductivity of corn cob ash blended cement mortar. The Pacific Journal of Science and Technology, 12(2), 106-111.

10. Maher, L. (1998). Automating the dreary measurements for loss on ignition. INQUA Sub-Commission on Data-Handling Methods, newsletter 18.

11. Bernal, L., Ke, X., Hussein, O. et al. (2016) Effect of testing condition on the loss on ignition results of anhydrous granulated blast furnace slags determined via thermogravimetry. In Segment on Concrete with Supplementary Cementitious Materials. International RILEM Conference on Materials, Systems and Structures in Civil Engineering (MSSCE), 21-24 Aug 2016, Lyngby.

12. Portland Cement Association. (2019). Cement \& Concrete Basics FAQs. Retrieved from https://www.cement.org/cement-concrete-applications/cement-and-concrete-basics-faqs

13. Külaots, I., Hurt, R. H., \& Suuberg, E. M. (2004). Size distribution of unburned carbon in coal fly ash and its implications. Fuel, 83(2), 223-230. doi: 10.1016/s0016-2361(03)00255-2

14. ASTM International. (2018). Standard Test Methods for Time of Setting of Hydraulic Cement by Vicat Needle (ASTM C191-18a). doi: 10.1520/c0191-18a

15. Madavath, K. (2018). Fineness test of cement by blaine's air permeability method (is-4031-part-2). Retrieved from https://wecivilengineers.wordpress.com/2018/04/06/fineness-test-of-cementby-blaines-air-permeability-method-is-4031-part-2/amp/

16. Olubajo, O., Osha, O., El-Natafty, U., \& Adamu, H. (2017). A study on Coal bottom ash and limestone effects on the hydration and physico-mechanical properties of ternary cement blends. Abubakar Tafawa Balewa University.

17. Georgescu, M., \& Saca, N. (2009). Properties of blended cements with limestone filler and fly ash content. Scientific Bulletin, Series B, 71(3), 11-22.

18. Gilliland, A. (2011). Evaluation of ternary blended cements for use in transportation concrete structures (Master's thesis), The University of Utah. Retrieved from http://cdmbuntu.lib.utah.edu/utils/getfile/collection/etd3/id/611/filename/474.pdf

19. Minh, L. T., \& Tram, N. X. T. (2017). Utilization of Rice Husk Ash as partial replacement with Cement for production of Concrete Brick. MATEC Web of Conferences, 97, 01121. doi:

10.1051/matecconf/20179701121

20. Myers, R., \& Montgomery, D. (1995). Response Surface Methodology: Process and Product Optimization Using Designed Experiments. New York: Wiley.

21. Arsenovic, M., Pezo, L., \& Radojevic, Z. (2012). Response surface method as a tool for heavy clay firing process optimization: Roofing tiles. Processing and Application of Ceramics, 6(4), 209-214. doi: $10.2298 /$ pac1204209a

22. Chauhan, B., \& Gupta, R. (2004). Application of statistical experimental design for optimization of alkaline protease production from Bacillus sp. RGR-14. Process Biochemistry, 39(12), 2115-2122. doi: 10.1016/j.procbio.2003.11.002

23. Koocheki, A., Taherian, A. R., Razavi, S. M. A., \& Bostan, A. (2009). Response surface methodology for optimization of extraction yield, viscosity, hue and emulsion stability of mucilage extracted from Lepidium perfoliatum seeds. Food Hydrocolloids, 23(8), 2369-2379. doi: 10.1016/j.foodhyd.2009.06.014

24. Lee, L., \& Wang, W. (1997). Biological Statistics. Beijing: Science press.

25. Wani, Y. B., \& Patil, D. D. (2017). An experimental design approach for optimization of spectrophotometric method for estimation of cefixime trihydrate using ninhydrin as derivatizing 
reagent in bulk and pharmaceutical formulation. Journal of Saudi Chemical Society, 21, S101S111. doi: 10.1016/j.jscs.2013.11.001

26. Matahula, W., \& Olubajo, O. (2018). Effects of Limestone and Coal Bottom Ash on Setting Time of Blended Portland Cement (Ternary Cement). Journal of Material Science \& Engineering, 07(05). doi: 10.4172/2169-0022.1000484 